\title{
The Improvement of Cardiac Performance by Amrinone, a New Cardiotonic Drug, in an Experimental Failing Heart Preparation of the Dog
}

\author{
Keisuke Satoh, M.D., Masahiko Maruyama, B.S., \\ and Norio TAIRA, M.D.
}

\section{SUMmary}

The cardiac effects of amrinone were studied in 5 heart-lung preparations of the dog. Amrinone improved the cardiac performance during pentobarbital-induced heart failure.

\section{Additional Indexing Words:}

Amrinone Heart-lung preparation Heart failure Positive inotropic action

\begin{abstract}
$\mathrm{A}$ MRINONE is a new orally effective cardiotonic drug developed for the treatment of the congestive heart failure. ${ }^{1,2)}$ The drug has a definite positive inotropic action in normal in situ hearts of the dog, ${ }^{11,2)}$ isolated Langendorff preparations of the guinea pig, ${ }^{3)}$ isolated papillary muscles or atria of the cat $^{1,3)}$ and rabbit, ${ }^{31}$ and isolated blood-perfused papillary muscles of the dog. ${ }^{4}$ However, the extent to which amrinone improves cardiac performance during experimentally-induced heart failure is equivocal. Farah and Alousi ${ }^{1)}$ reported that amrinone completely restored the cardiac function curve of dog heart-lung preparations after induction of heart failure by pentobarbital administration, whereas Onuaguluchi and $T a n z^{3}$ reported that the force of contraction of the guinea-pig Langendorff preparation depressed by verapamil failed to attain control values after amrinone administration. ${ }^{3)}$ Furthermore, Farah and Alousi ${ }^{1)}$ did not discuss how amrinone affected the heart rate and force of contraction of the dog heart-lung preparations. The present experiments were designed to obtain detailed information about the effects of amrinone on the failing heart. We used the dog heart-lung preparation in which cardiac failure was produced by pentobarbital.
\end{abstract}

From the Department of Pharmacology, Tohoku University School of Medicine, Sendai 980, Japan.

Received for publication February 15, 1982. 


\section{Materials And Methods}

The heart-lung preparation of the dog was used. The method used was essentially the same as described elsewhere in detail,5),6) except that electronic measuring devices were used. Five mongrel dogs, weighing 7-10 Kg, were anesthetized with sodium pentobarbital ( $30 \mathrm{mg} / \mathrm{Kg}$, i.v.). Blood coagulation was prevented with sodium heparin (500 units/Kg, i.v.). The volume of blood primed in the venous reservoir was 300-750 ml. The cardiac output was measured with an electromagnetic flow meter (Nihon Kohden, MF-46). The right atrial pressure was measured with a pressure transducer (Nihon Kohden, LPU-0.1). The force of contraction was measured with a Walton-Brodie strain-gauge arch, stitched to the surface of the left ventricle. The heart rate was measured with a heart rate meter (San-ei Instrument, 2040) triggered by $\mathbf{R}$ waves of lead II of EGG. All recordings were made on a rectilinear recorder (San-ei Instrument, 8S). To determine the ability of the heart to respond to an increased venous supply, the inflow level (height of the venous reservoir) was raised stepwise to $5 \mathrm{~cm}$ and $10 \mathrm{~cm}$ above the basal level (competence test). At each inflow level a competence index was obtained by dividing the increase in right atrial pressure $\left(\mathrm{cm} \mathrm{H}_{2} \mathrm{O}\right)$ by $5 \mathrm{~cm}$ or $10 \mathrm{~cm}$ (elevated height of the venous reservoir), and the cardiac function curves were constructed. Amrinone (Sterling-Winthrop) was dissolved in $0.1 \mathrm{~N}$ lactic acid in a concentration of $10 \mathrm{mg} / \mathrm{ml}$. The amrinone solution was administered into the venous reservoir in a cumulative way. The results are expressed as mean values \pm SEM, unless otherwise stated. Student's t-test was used and a $p$ value less than 0.05 was considered significant.

\section{Results}

When basal cardiac variables were stable, sodium pentobarbital was administered into the reservoir in $50 \mathrm{mg}$ steps up to a total of $90 \pm 22$ (S.D.) mg $(n=5)$. With these doses of sodium pentobarbital, the cardiac output, heart rate, and force of contraction decreased and the right atrial pressure

Table I. The Values of Cardiac Variables before and after Pentobarbital Administration

\begin{tabular}{l|lccc}
\hline & $\begin{array}{c}\text { Cardiac } \\
\text { output } \\
(\mathrm{ml} / \mathrm{min})\end{array}$ & $\begin{array}{c}\text { Right atrial } \\
\text { pressure } \\
\left(\mathrm{cm} \mathrm{H}_{2} \mathrm{O}\right)\end{array}$ & $\begin{array}{c}\text { Heart rate } \\
(\text { beats/min) }\end{array}$ & $\begin{array}{c}\text { Contractility } \\
(\%)\end{array}$ \\
\hline $\begin{array}{l}\text { Control } \\
\begin{array}{l}\text { Pentobarbital treatment } \\
90 \pm 22 \text { (S.D.) } \mathrm{mg}\end{array}\end{array}$ & $740 \pm 81$ & $2.5 \pm 0.6$ & $145 \pm 10$ & 100 \\
\hline
\end{tabular}

* Significantly different from control values. 


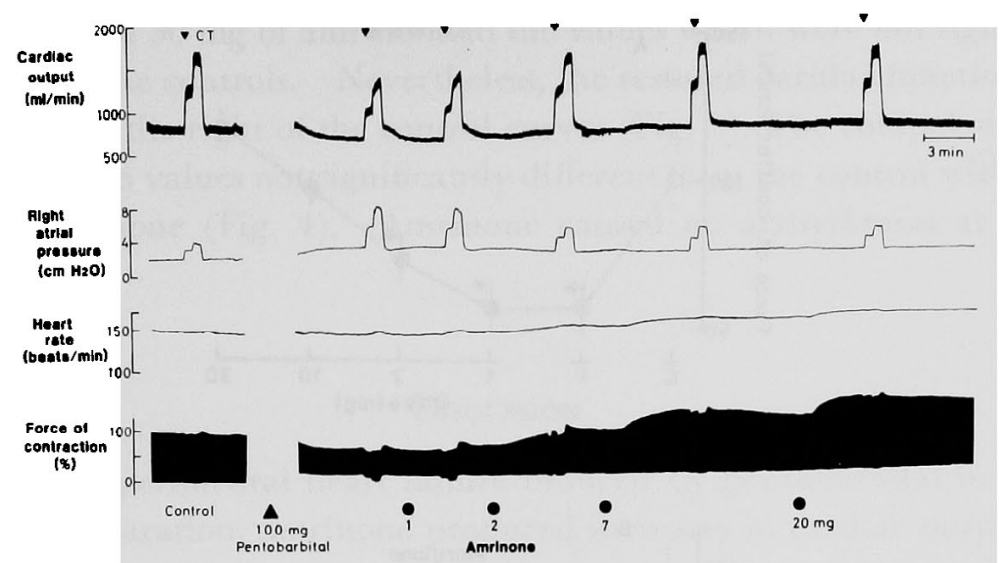

Fig. 1. Effects of amrinone on the cardiac output, right atrial pressure, heart rate, and force of contraction in a heart-lung preparation of the dog. CT $=$ competence test.

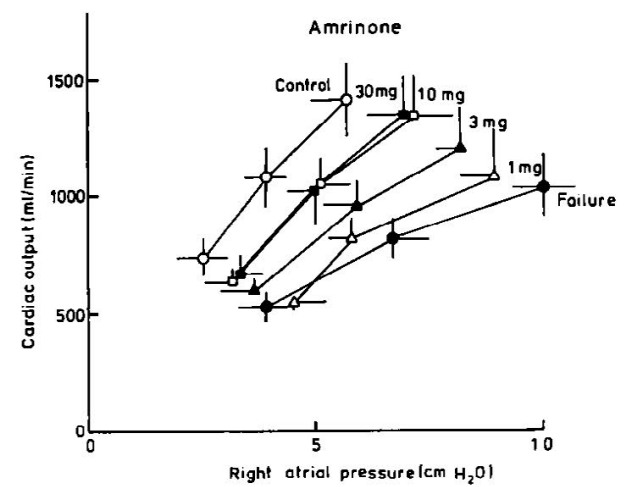

Fig. 2. Gardiac function curves obtained by elevating the height of the venous reservoir. Control $(\mathrm{O})$, failure $(\Theta)$. Amrinone in cumulative doses: $1 \mathrm{mg}(\Delta), 3 \mathrm{mg}(\Delta), 10 \mathrm{mg}(\square), 30 \mathrm{mg}(\mathbf{D})$.

increased gradually (Figs. 1, 2). The mean decreases in cardiac output and force of contraction, attained after the final dose of pentobarbital, were about $30 \%$ and $40 \%$ of respective controls. The values of cardiac variables before and after the final pentobarbital dose are shown in Table I. Under these conditions, amrinone was administered cumulatively into the reservoir in doses ranging from $1 \mathrm{mg}$ to a total of $30 \mathrm{mg}$. One of experiments is illustrated in Fig. 1 and the summarized results from 5 preparations are shown in Figs. 2, 3, and 4. Amrinone administration gradually increased the cardiac output (Figs. 1, 2), force of contraction and heart rate (Figs. 1, 3), and decreased the right atrial pressure (Figs. 1,2) in a dose-dependent manner. These actions of amrinone were slow in onset and long-lasting. The force of contraction recovered completely with $10 \mathrm{mg}$ of amrinone and increased further beyond the 

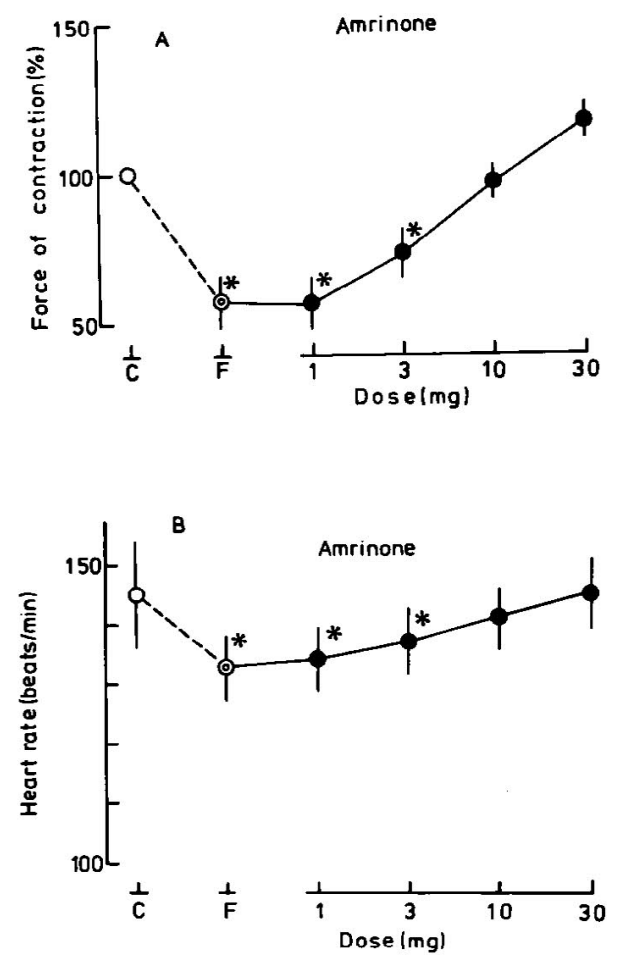

Fig. 3. Dose-response curves for changes in force of contraction (A) and heart rate (B). $\mathrm{C}=$ control; $\mathrm{F}=$ failure produced by pentobarbital. * Significantly different from control.

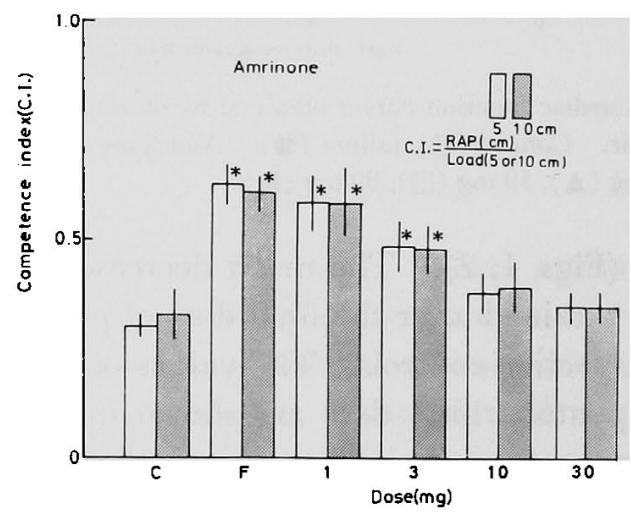

Fig. 4. Competence index obtained from the competence test. $\mathrm{C}=$ control; $\mathrm{F}=$ failure. $\mathrm{RAP}=$ right atrial pressure. * Significantly different from control.

control value (the value before pentobarbital) with a $30 \mathrm{mg}$ dose (Fig. 3). The heart rate was restored to the control value with $30 \mathrm{mg}$ of amrinone (Fig. 3). The cardiac function curve, depressed by pentobarbital, was re- 
stored by 10 and $30 \mathrm{mg}$ of amrinone to the values which were not significantly different from the controls. Nevertheless, the restored caridac function curves were located to the right of the control curves (Fig. 2). The competence index also recovered to values not significantly different from the control with 10 and $30 \mathrm{mg}$ of amrinone (Fig. 4). Amrinone caused no arrhythmias at all dose levels tested.

\section{Discussion}

During experimental heart failure induced by pentobarbital in the dog heart-lung preparation, amrinone produced increases in cardiac output, force of contraction, and heart rate, and a decrease in right atrial pressure. The values of these cardiac variables after amrinone administration were not significantly different from the control values (the values before pentobarbital). The competence index also recovered to the control value. Thus, the present results are consistent with those obtained by Farah and Alousi' from the same sort of preparation ${ }^{1)}$ but are at variance with those obtained from the guinea-pig Langendorff preparation, where heart failure was induced by verapamil. ${ }^{3)}$ At present, it is not clear whether the discrepancy is due to differences in species, preparations or cardiodepressant drugs. Although the results are roughly consistent with those obtained by Farah and Alousi, ${ }^{1)}$ the restoration of the cardiac function curves after amrinone administration was different. In their experiments, the cardiac function curves depressed by pentobarbital were shifted to left of the control curve after administration of $10 \mathrm{mg}$ of amrinone. On the other hand, in the present experiments, the cardiac function curve, depressed in a similar way, was located to the right of the control curve even with $30 \mathrm{mg}$ of amrinone.

It is clear that amrinone is a rather weak cardiotonic drug, as assessed in the present experimental heart failure model. Nevertheless, amrinone is still a potential drug for heart failure. ${ }^{7), 8)}$ Amrinone, unlike catecholamines, has been reported to increase the heart rate only slightly in doses which producc a sizable increase in force of contraction. ${ }^{1)-3)}$ In the present experiments, doses of amrinone which restored the cardiac function curve virtually to the control did not increase the heart rate beyond the control value. Furthermore, amrinone, unlike digitalis, produced no arrhythmias. Digitalis is also known to be a vasoconstrictor. As opposed to digitalis, amrinone has a coronary vasodilator action that increases the supply of oxygen to the myocardium, ${ }^{4,9)}$ and a peripheral vasodilator action which reduces the load on the failing heart. ${ }^{10)}$ In addition to these actions, amrinone has a tracheodilator action in the dog. ${ }^{11)}$ 


\section{AGKNOWLEDGMENT}

We are grateful to Sterling-Winthrop Research Institute, New York, USA for a generous supply of amrinone.

\section{REFERENCES}

1. Farah AE, Alousi AA: New cardiotonic agents. A search for digitalis substitute. Life Sci 22: 1139,1978

2. Alousi AA, Farah AE, Lesher GY, Opalka GJ Jr: Cardiotonic activity of amrinone-Win 40680 [5-Amino-3, 4'-bipyridin-6 (1H)-one]. Circulat Res 45: 666, 1979

3. Onuaguluchi G, Tanz RD: Cardiac effects of amrinone on rabbit papillary muscle and guinea pig Langendorff heart preparations. J Cardiovasc Pharmacol 3: 1342, 1981

4. Yamashita S, Taira N: Assessment of cardiac and coronary dilator effects of amrinone by the use of isolated, blood-perfused canine heart preparations. J Cardiovasc Pharmacol (in press)

5. Krayer O: Versuche am insuffizienten Herzen. Naunyn-Schmiedeberg's Arch Exp Path Pharmakol 162: 1, 1931

6. Krayer $\mathrm{O}$, Mendez $\mathrm{R}$ : Studies on veratrum alkaloids $\mathrm{I}$. The action of veratrine upon the isolated mammalian heart. J Pharmacol Exp Ther 74: 350, 1942

7. LeJemtel TH, Keung E, Sonnenblick EH, Ribner HS, Matsumoto M, Davis R, Schwartz W, Alousi AA, Davolos D: Amrinone. A new non-glycosidic, non-adrenergic cardiotonic agent effective in the treatment of intractable myocardial failure in man. Girculation 59: 1098, 1979

8. LeJemtel TH, Keung E, Ribner HS, Davis R, Wexler J, Blaufox MD, Sonnenblick EH: Sustained beneficial effects of oral amrinone on cardiac and renal function in patients with severe congestive heart failure. Am J Cardiol 45: 123, 1980

9. Grupp I, Grupp G, Fowler NO, Gabel M, Alousi AA, Millard RW: Hemodynamic and inotropic responses of normal and depressed dog hearts to amrinone. Fed Proc 39: 976, 1980

10. Alousi AA, Helstosky A: Amrinone. A positive inotropic agent with a direct vasodilatory activity in the canine isolated perfused hind limb preparation. Fed Proc 39: 855, 1980

11. Maruyama M, Satoh K, Taira N: Effects of amrinone on the tracheal musculature and vasculature of the dog. Jpn J Pharmacol 31 : 1095, 1981 